\title{
Relationship of anthropometric indicators with blood pressure levels and the risk of hypertension in Nigerian adults
}

\author{
Rufus A Adedoyin' \\ Chidozie E Mbada ${ }^{2}$ \\ Luqman A Bisiriyu ${ }^{3}$ \\ Rasaaq A Adebayo ${ }^{4}$ \\ Michael O Balogun ${ }^{4}$ \\ Anthony O Akintomide ${ }^{4}$ \\ 'Department of Medical \\ Rehabilitation; ${ }^{2}$ Physiotherapy \\ Department, Obafemi Awolowo \\ University Teaching Hospital Complex, \\ Ile-Ife, Nigeria; ${ }^{3}$ Department \\ of Demography and Social Statistics; \\ ${ }^{4}$ Department of Medicine, Obafemi \\ Awolowo University, Ile-Ife, Nigeria
}

Correspondence: Rufus A Adedoyin Department of Medical Rehabilitation, College of Health Sciences, Obafemi Awolowo University, lle-Ife, Nigeria Tel +2348033829978

Email radedoyi@yahoo.com

\begin{abstract}
Background and purpose: Studies on cardiovascular risks in relation to anthropometric factors are limited in Sub-Sahara Africa. The aims of this study were to examine the relationship between anthropometric parameters and blood pressure; and to evaluate body mass index (BMI) across the range of underweight and obesity as a primary risk factor of hypertension in adult Nigerians.
\end{abstract}

Material and methods: 2097 adults aged between 20 and 100 years consented and participated in this door-to-door survey. All participants underwent blood pressure and anthropometric measurements using standard procedures. The population study was separated in normotensive and hypertensive males and females and the possible risk for hypertension were categorized into different classes of value based on BMI definition.

Results: The relative risks (odds ratio [OR] and 95\% confidence interval [CI]) of developing hypertension among the obese compared with the underweight, normal weight, and overweight persons were (OR 5.75; CI 5.67-5.83), (OR 1.73; CI 1.65-1.81), and (OR 1.54; CI 1.46-1.62) for all the participants, respectively. Among obese $\left(\mathrm{BMI} \geq 30.0 \mathrm{Kg} / \mathrm{m}^{2}\right)$ males, the OR for hypertension was three times (OR 2.78; CI 2.76-2.80) that of normal weight (BMI $\geq 18.5-24.9 \mathrm{Kg} / \mathrm{m}^{2}$ ) males. Females with obesity had a risk of hypertension three times (OR 3.34; CI 3.33-3.35) that of normal weight females.

Conclusion: Our results indicated that the there was a significant positive correlation of obesity indicator with blood pressure. In Nigeria, we found a strong gradient between higher BMI and increased risk of hypertension among all ages. Approaches to reduce the risk of hypertension may include prevention of overweight and obesity.

Keywords: body mass index, obesity, blood pressure, risk of hypertension

\section{Introduction}

Several epidemiological studies from different populations have reported significant association between different anthropometric indicators and blood pressure levels (Stamler 1991; Guagnano et al 1994; Gupta and Mehrishi 1997; Kaufman et al 1997; Olatunbosun et al 2000; Bose et al 2003; Shanthirani et al 2003). Some anthropometric measures or indexes, such as body mass index (BMI), and other measures of body fatness have been used in most of these studies to analyze the association between adiposity and cardiovascular risk factors (Han et al 1995; Olatunbosun et al 2000; Guagnano et al 2001; Sergeant et al 2002; Belahsen et al 2004). Most of these studies have shown linear relationships between anthropometric measures and the risk of cardiovascular disease (Stamler 1991; Guagnano et al 1994; Kaufman et al 1997; Kadiri et al 1999; Okosun et al 1999; Olatunbosun et al 2000; Yekeen et al 2003). These associations between body fatness using different indexes have been consistently observed, but remain poorly understood (Kaufman et al 1997) and the mechanistic explanations for the phenomenon are still being debated, and no biological model of the process has been established (Han 1994). 
In Sub-Saharan Africa (SSA), cardiovascular diseases have been projected to be the leading cause of morbidity and mortality by the year 2020 especially considering epidemic expansion (Pearson 1999). Reports about cardiovascular risk in relation to anthropometric factors are limited SSA (Kamadjeu et al 2006). Secondary data from the developed nations are often extrapolated for local use in Africa. Little is known about the anthropometry-blood pressure relationship in indigent Nigerian adult population, while no data seem to be available on the relationship between body-fat distribution and the risk of hypertension in the same population. Although obesity is known to increase the risk of hypertension, few studies have evaluated BMI across various ranges as a primary risk factor (Gelber et al 2007). This present study was therefore undertaken to examine the relationship between different anthropometric indicators and blood pressure levels and to evaluate BMI across the range of underweight and obesity as a primary risk factor of hypertension in adult Nigerians.

\section{Material and methods}

This study was conducted in the ancient Yoruba town of IleIfe, in the south-western part of Nigeria. Ile-Ife, though in the Yoruba region of Nigeria, is a heterogeneous community with a high influx of Nigerians from other tribes because of the high presence of educational, governmental, banking, and business institutions among others. Using the World Health Organization (WHO 2004) guidelines for conducting community surveys, five out of the eleven political wards into which Ife central local government area was divided were randomly chosen. In each ward, 3 census enumeration areas were randomly selected. Each enumeration area was expected to include approximately 150 adults aged 20 years and older. Houses with odd numbers were selected for survey. All eligible and consented adults were recruited until approximately 150 participants were measured in an enumeration area. The study design intended to recruit a total of 2250 adults. However, a total of 2097 adults whose ages ranged between 21 and 100 years consented and participated in the door-to-door house survey therefore yielding a response rate of $93.2 \%$.

\section{Procedure}

The consent and permission of the chiefs and elders in each of the quarters within the five political wards was sought and obtained. The participants were fully informed about the purpose of the study and their consents were obtained before measurements were taken. Local dialect was used for participants who were not literate in the English language.

Data were collected at the close of day when the participants could be met at home (1600-2000 hrs). After about $10 \mathrm{~min}$ of quiet sitting, three readings of blood pressure (BP) were taken at intervals of 3-5 minutes using an electronic BP monitor (Omron Healthcare Inc., Vernon Hills, IL, USA) following the manufacturer manual guide. The mean BP value was used for analysis. The heart rate (HR) readings were also obtained from the electronic BP monitor. In the pilot study, good agreement was found between the readings from the automated BP device and measurements taken with a conventional sphygmomanometer $(\mathrm{r}=0.97)$. The appropriate cuff size $(13 \times 23 \mathrm{~cm}$ or $16 \times 30 \mathrm{~cm})$ was used. Based on the current definition of hypertension recently published by the Seventh Joint National Committee on Prevention, Detection, Evaluation, and Treatment of High Blood Pressure guidelines (Chobanian et al 2003) and the WHO and International Society of Hypertension guidelines (WHO-ISH 1999); a cut off point of 140/90 mmHg for hypertension was adopted. Those with the BP of less than or equal to $140 / 90 \mathrm{mmHg}$ were considered normotensive while those with higher values or who reported to be on new antihypertensive medications were classified as hypertensive. The population study was separated into normotensive and hypertensive male and females.

Height was measured with a standiometer. The participant's heels, the back, and the occiput were touching the scale with the participants looking straight ahead during measurement. The height of each participant was measured to the nearest $0.1 \mathrm{~cm}$. Weight was measured with a bathroom weighing scale calibrated from $0-120 \mathrm{~kg}$ with the participant standing with shoes removed. Body weight was measured in kilograms to the nearest $1.0 \mathrm{~kg}$. BMI was calculated by dividing weight in kilograms by height in meters squared $\left(\mathrm{Wkg} / \mathrm{Hm}^{2}\right)$. The participants' ages were also recorded.

Using the WHO classification (WHO 1997), four categories of BMI were identified as follows: underweight, $<18.5 \mathrm{~kg} / \mathrm{m}^{2}$; normal, $\geq 18.5-24.9 \mathrm{~kg} / \mathrm{m}^{2}$; overweight, $\geq 25.0-29.9 \mathrm{~kg} / \mathrm{m}^{2}$; and obesity, $>30 \mathrm{~kg} / \mathrm{m}^{2}$.

\section{Data analysis}

The data analysis was carried out using SPSS version 13.0 software (SPSS Inc., Chicago, IL, USA). The descriptive statistics of means with $95 \%$ CI were used to summarize the data collected. Means were compared by using independent t-test. Pearson's partial correlation coefficients were used for continuous variables. Chi square test was used to analyze the 
association between BMI category and the distribution of hypertension. Odds ratio was used to determine the relative risk of hypertension in the study population. Linear regression analysis was used to assess the influence of different anthropometric indicators on the systolic blood pressure (SBP), diastolic blood pressure (DBP), and HR. One-way analysis of variance (ANOVA) was used to compare the general characteristics of the participants on age stratification. The level of significance of all test was taken at $P<0.05$.

\section{Results}

A total of 2097 adults participated in the study (886 [42.2\%] men and 1211 [57.8\%] women). The ages of the participants ranged from 20 to 100 years. The mean and 95\% confidence intervals for age, weight, height, and BMI were 44.2 (43.0-44.5) yrs, 64.9 (64.6-65.2) kg, 1.64 (1.62-1.66) m, $24.2(24.1-24.3) \mathrm{kg} / \mathrm{m}^{2}$, respectively. The mean and 95\% CI BP of all the participants were 126.5 (126.1-126.9) $\mathrm{mmHg}$ and 77.7 (77.5-77.8) $\mathrm{mmHg}$ for SBP and DBP, respectively while the HR was 73.7 (73.5-73.9) beats/min. The general characteristics of the participants by gender are presented in Table 1. The males were significantly taller and heavier than their female counterparts. However, the females had a significant higher BMI than the males.

The Pearson's correlation matrix for the association between anthropometric indicators and each of SBP, DBP, and HR by gender is presented in Table 2. Weight and BMI indicated a significant positive but weak correlation with SBP, DBP, and HR, respectively. However, height was not significantly correlated with the cardiovascular parameters.

Linear regression models were fitted for SBP, DBP, and $\mathrm{HR}$ as dependent variables and age, height, weight, and BMI as independent variables controlled for sex to determine their influence on the variance of these dependent variables.
The regression analysis showed a significant linear relationship between dependent variables and the independent variables. $\mathrm{R}^{2}$ was 5\%-9\%. Age, height, weight, and BMI respectively are predictors of blood pressure and HR. Multiple regression equation for predicting SBP, DBP, and HR is thus:

$$
\mathrm{Y}=\mathrm{B} 0+\mathrm{B} 1 \times 1+\mathrm{B} 2 \times 2+\mathrm{B} 3 \times 3+\mathrm{B} 4 \times 4 \text {. }
$$

Where $\mathrm{Y}$ is the dependent variable; $\mathrm{B} 0$ is a constant; B1-B4 are coefficient of the independent variables; $1-4$ are the dependent variables (age, height, weight, and BMI).

$$
\begin{aligned}
\mathrm{SBP}= & 45.576+0.381(\text { age })+24.462 \text { (height })-0.307 \\
& (\text { weight })+1.532(\mathrm{BMI}) . \\
\mathrm{DBP}= & -4.594+0.121(\text { age })+41.068 \text { (height })-0.424 \\
& \quad(\text { weight })+1.536(\mathrm{BMI}) . \\
\mathrm{HR}= & 99.134-0.026 \text { (age) }-18.638 \text { (height })+0.152 \\
& (\text { weight })-0.149(\mathrm{BMI}) .
\end{aligned}
$$

The study population was separated in normotensive and hypertensive males and females and they were subdivided into different classes using the BMI category as the possible risk factor for hypertension. Of the total study population, $30.4 \%$ (638) were hypertensive with a percentage distribution of $1.19 \%, 14.9 \%, 13.5 \%$, and $8.7 \%$ in the underweight, normal, overweight, and obesity categories, respectively. $69.9 \%$ (1459) of the study population were normotensive with a percentage distribution of $4.9 \%, 44.6 \%, 13.9 \%$, and $6.2 \%$ in the underweight, normal, overweight, and obesity categories, respectively. The rates of hypertension among the males in the study population were; $27 \%, 25.2 \%, 34.8 \%$, and $48.3 \%$ for the underweight, normal, overweight, and obesity categories, respectively. While among the females, $16.5 \%$, $25.0 \%, 36.9 \%$, and $52.5 \%$ belong to the underweight, normal,

\begin{tabular}{|c|c|c|c|c|}
\hline \multirow[t]{2}{*}{ Dependent variables } & \multirow{2}{*}{$\begin{array}{l}\text { Male participants } \\
(n=334)\end{array}$} & \multicolumn{3}{|c|}{ Female participants } \\
\hline & & $(n=696)$ & t-cal & p-value \\
\hline Age & $44.2 \pm 10.7$ & $44.2 \pm 12.3$ & -0.072 & 0.943 \\
\hline Height & $\mathrm{I} .67 \pm 0.08$ & $1.62 \pm 0.07$ & 13.77 & $0.000 *$ \\
\hline Weight & $66.1 \pm 12.2$ & $64.0 \pm 13.4$ & 3.729 & $0.000^{*}$ \\
\hline BMI & $23.8 \pm 4.19$ & $24.5 \pm 4.99$ & -3.209 & $0.00 I^{*}$ \\
\hline SBP & $127.5 \pm 18.0$ & $125.8 \pm 20.9$ & 1.905 & 0.057 \\
\hline DBP & $77.3 \pm 10.8$ & $77.9 \pm 11.9$ & -1.216 & 0.224 \\
\hline HR & $72.4 \pm 9.94$ & $74.6 \pm 11.7$ & -4.388 & $0.000 *$ \\
\hline
\end{tabular}
overweight, and obesity categories, respectively.

Table 3 shows the Chi square analysis of the association between the distribution of percentage of hypertension and the different BMI category for all participants and by gender

Table I Independent t-test comparison between the physical characteristics and physiological response of the male and the female participants

Note: *Indicate significance at $\mathrm{P}<0.05$.

Abbreviations: BMI, body mass index; SBP, systolic blood pressure; DBP, diastolic blood pressure; HR, heart rate. 
Table 2 Correlation between cardiovascular parameters, physical characteristics, and the measures of adiposity of all the participants

\begin{tabular}{llll}
\hline Dependent variables & \multicolumn{3}{l}{ Correlation coefficient $(\mathbf{r})$} \\
\cline { 2 - 4 } & SBP & DBP & HR \\
\hline Height $(\mathrm{m})$ & -0.029 & 0.039 & -0.045 \\
& 0.076 & 0.038 & 0.179 \\
Weight $(\mathrm{kg})$ & 0.150 & 0.164 & 0.083 \\
& 0.000 & 0.000 & 0.000 \\
BMI $\left(\mathrm{kg} / \mathrm{m}^{2}\right)$ & 0.175 & 0.156 & 0.109 \\
& 0.000 & 0.000 & 0.000
\end{tabular}

Notes: $* \mathrm{P}<0.05 ; * * \mathrm{P}<0.001$.

Abbreviations: BMI, body mass index; SBP, systolic blood pressure; DBP, diastolic blood pressure; $H R$, heart rate.

in the hypertensive population. The Chi square test revealed a statistical significant association between hypertension prevalence and BMI categories among all the participants and the male participants only on gender stratification. However, all the analyses were stratified into four groups according to age (20-40, 41-60, 61-80, and 81-100 years). There were statistically significant trends of increasing BMI and blood pressure levels with increasing age except for those at age group
81 years and older. The summary of the one-way ANOVA and least significant difference post-hoc multiple comparison of the participants' general characteristics, BP levels and HR based on age stratification is presented in Table 4. The Chi square test showed a statistical significant association between percentage of distribution of hypertension in each BMI category and age as presented in Table 5. The statistically significant trends of increasing prevalence in the risk of hypertension increased directly with age except at age 81 years and older among the obese category. The trends of prevalence of risk of hypertension among the overweight category increased with increasing age except at age 60 year and older. These trends were not consistently observed among the underweight and normal range subjects.

From the study population, the risk of hypertension among those with BMI $\geq 30.0 \mathrm{~kg} / \mathrm{m}^{2}$ (obese) was about six times (OR 5.75; CI 5.67-5.83) that of those with BMI $>18.5 \mathrm{~kg} / \mathrm{m}^{2}$ (underweight), while the OR for hypertension was approximately two times for obese persons than those in the normal weight (BMI $\left.\geq 18.5-24.9 \mathrm{~kg} / \mathrm{m}^{2}\right)(\mathrm{OR} 1.73$; CI 1.65-1.81) and overweight $\left(\mathrm{BMI}<25.0-29.9 \mathrm{~kg} / \mathrm{m}^{2}\right)(\mathrm{OR} 1.54 ; \mathrm{CI} 1.46-1.62)$ categories, respectively. Among males with BMI $\geq 30.0 \mathrm{~kg} / \mathrm{m}^{2}$ (obese) the OR for hypertension was approximately three times

Table 3 Chi square analysis of the association between the distribution of percentage of hypertension and the different body mass index (BMI) category for all participants and by gender in the hypertensive population

\begin{tabular}{|c|c|c|c|c|c|}
\hline & BMI category & Number & Percentage & $\mathbf{X}^{2}$ & $\mathbf{p}$ \\
\hline \multicolumn{6}{|l|}{ All } \\
\hline & Underweight & 30 & 4.70 & 9.961 & 0.019 \\
\hline & Normal weight & 354 & 55.5 & & \\
\hline & Overweight & 133 & 20.9 & & \\
\hline & Obesity & 121 & 19.0 & & \\
\hline Total & & 638 & & & \\
\hline \multicolumn{6}{|l|}{ Male } \\
\hline & Underweight & 10 & 5.13 & 9.736 & 0.021 \\
\hline & Normal weight & 115 & 59.0 & & \\
\hline & Overweight & 52 & 26.7 & & \\
\hline & Obesity & 18 & 9.23 & & \\
\hline Total & & 195 & & & \\
\hline \multicolumn{6}{|c|}{ Female } \\
\hline & Underweight & 23 & 5.19 & $0.38 I$ & 0.944 \\
\hline & Normal weight & 206 & 46.5 & & \\
\hline & Overweight & 111 & 25.1 & & \\
\hline & Obesity & 103 & 23.3 & & \\
\hline Total & & 443 & & & \\
\hline
\end{tabular}

Notes: $p$ is significant at 0.05 . 
Table 4 Summary of the one-way ANOVA and least significant difference post-hoc multiple comparisons of the participants' general characteristics, BP levels, and HR based on age stratification

\begin{tabular}{|c|c|c|c|c|c|c|}
\hline \multirow[t]{3}{*}{ Variables } & $20-40$ yrs & $4 I-60$ yrs & $6 \mathrm{I}-80 \mathrm{yrs}$ & $8 \mathrm{I}-100$ yrs & \multirow[b]{3}{*}{$\mathbf{F}$ ratio } & \multirow[b]{3}{*}{ p-value } \\
\hline & $\mathbf{N}=2 I I$ & $\mathbf{N}=302$ & $N=104$ & $\mathbf{N}=\mathbf{2 I}$ & & \\
\hline & $\mathrm{X} \pm \mathrm{SD}$ & $X \pm S D$ & $X \pm S D$ & $X \pm S D$ & & \\
\hline Age & $34.4 \pm 5.43^{\mathrm{a}}$ & $50.0 \pm 5.63^{b}$ & $68.3 \pm 5.25^{c}$ & $88.4 \pm 8.56^{d}$ & 1204.6 & 0.000 \\
\hline Height & $1.65 \pm 0.09^{a}$ & $1.64 \pm 0.09^{\mathrm{a}}$ & $1.59 \pm 0.09^{b}$ & $1.63 \pm 0.10^{\mathrm{a}}$ & 13.4 & 0.000 \\
\hline Weight & $67.6 \pm 13.6^{\mathrm{a}}$ & $68.6 \pm 14.8^{\mathrm{a}}$ & $67.4 \pm 14.8^{a}$ & $63.9 \pm 15.6^{a}$ & 1.03 & 0.378 \\
\hline BMI & $25.0 \pm 5.34^{a}$ & $25.6 \pm 5.45$ & $26.7 \pm 5.64^{b}$ & $23.7 \pm 4.38^{\mathrm{a}}$ & 3.62 & 0.013 \\
\hline SBP & $145 \pm 17.0^{a}$ & $152 \pm 20.0^{b}$ & $164 \pm 19.0^{c}$ & $162 \pm 19.2^{c}$ & 27.96 & 0.000 \\
\hline DBP & $90 \pm 11.9^{a}$ & $92 \pm 11 . I^{b}$ & $90 \pm 11.9$ & $92 \pm 4.99$ & 3.29 & 0.020 \\
\hline HR & $78 \pm 12.5^{a}$ & $81 \pm 9.1^{a}$ & $78 \pm 12.4^{a}$ & $80 \pm 8.2^{\mathrm{a}}$ & 1.65 & 0.177 \\
\hline
\end{tabular}

Notes: ${ }^{a-e} \mathrm{P}$ is significant at 0.05 . For a particular variable, mode means with different superscript are significantly $(P<0.05)$ different. Mode means with same superscripts are not significantly $(P>0.05)$ different. When only one contrast is significant, one of the cell means has no superscript attached. The pair of cell means that is significant has different superscripts.

Abbreviations: ANOVA, analysis of variance; BMI, body mass index; BP, blood pressure; DBP, diastolic blood pressure; HR, heart rate; SBP, systolic blood pressure; SD, standard deviation.

that of males with BMI $<18.5 \mathrm{~kg} / \mathrm{m}^{2}$ (underweight) (OR 2.50; CI 2.48-2.52) it was also about three times higher than among males with $\mathrm{BMI} \geq 18.5-24.9 \mathrm{~kg} / \mathrm{m}^{2}$ (normal weight) (OR 2.78; CI 2.76-2.80), while it was about two times higher than among males with BMI $<25.0-29.9 \mathrm{~kg} / \mathrm{m}^{2}$ (overweight) (OR 5.19; CI 5.17-5.20). Females with BMI $\geq 30.0 \mathrm{~kg} / \mathrm{m}^{2}$ (obese) had a risk of hypertension six times (OR 5.58; CI 5.57-5.59) that of females with BMI $>18.5 \mathrm{~kg} / \mathrm{m}^{2}$ (underweight), the risk of hypertension is about three times higher (OR 3.34; CI 3.33-3.35) among obese women than their normal weight $\left(\geq 18.5-24.9 \mathrm{~kg} / \mathrm{m}^{2}\right)$ counterparts, while the risk is twice (OR 1.90; CI 1.89-1.91) that of the overweight females $\left(\mathrm{BMI}>25.0-29.9 \mathrm{~kg} / \mathrm{m}^{2}\right)$.

\section{Discussion}

Hypertension is a risk factor for cardiovascular disease and is typically obesity-related (Gus et al 2004). Most examining the risk of hypertension associated with obesity have been based on data from developed countries. Anthropometric indicators such as BMI have been recognized for estimating cardiovascular disease risk factors, particularly due to their positive association with hypertension (Pi-Sunyer 1993; Han et al 1997; Cox et al 1998; Olatunbosun et al 2000; Guagnano et al 2001; Sergeant et al 2002; Belahsen et al 2004). BMI has long been recognized in clinical settings and in epidemiological research as a surrogate estimate of the degree of body fatness because it is easily evaluated.

The well known correlates of anthropometric indicators and BP have again been confirmed in this study. The finding of this study corroborates the earlier investigations that reported significant positive correlation of anthropometric factors such as BMI with SBP and DBP (Seidell et al 1991; Kadiri et al 1999; Hsieh et al 2000; Olatunbosun et al 2000; Shahbazpour 2003; Yekeen et al 2003; Gus et al 2004).

Table 5 Chi square analysis of the association between percentage of distribution of hypertension in each body mass index category and age

\begin{tabular}{|c|c|c|c|c|c|c|}
\hline Years & $20-40$ & $41-60$ & $61-80$ & $81-100$ & & \\
\hline \multirow[t]{2}{*}{$\mathbf{N}$} & 211 & 302 & 104 & 21 & & \\
\hline & & & & & $\mathbf{X}^{2}$ & $P$ value \\
\hline \multicolumn{7}{|c|}{ Body mass index category } \\
\hline Underweight & $17(8.1 \%)$ & 14 (4.6\%) & $2(1.9 \%)$ & $0(0.0 \%)$ & \multirow[t]{4}{*}{20.98} & \multirow[t]{4}{*}{0.013} \\
\hline Normal weight & $92(43.6 \%)$ & $120(39.7 \%)$ & $36(34.6 \%)$ & $13(61.9 \%)$ & & \\
\hline Overweight & $62(29.4 \%)$ & $94(31.1 \%)$ & $32(30.8 \%)$ & $5(23.8 \%)$ & & \\
\hline Obesity & $40(19.0 \%)$ & $74(24.5 \%)$ & $34(32.7 \%)$ & $3(14.3 \%)$ & & \\
\hline
\end{tabular}


Though, independent associations between BMI and SBP/ DBP have been reported in earlier studies (Seidell et al 1991; Bonorra et al 1992; Assmann 1993; Hsieh et al 2000; Shahbazpour 2003), however, the correlation coefficients of these different associations were found to be constantly small, indicating that relationship between BMI and blood pressure is somewhat complex. The rates of hypertension found in this study among the underweight, normal, overweight, and obesity categories respectively per gender was high as each BMI category had a prevalence that overshot the $10 \%$ trigger-point (Mabadeje 1999).

The performance of different anthropometric measurements and indices in predicting obesity-related outcomes has been addressed in several reports. Cox and colleagues (1998) have examined the predictive ability of simple anthropometric indices for the development of cardiovascular disease (CVD) over 7 years. From this study, we found age, height, weight, and BMI as significant predictors of SBP, DBP, and HR. We confirmed that anthropometric factors are predictive of BP.

The finding of this study showed that BMI was statistically associated with the incidence of hypertension. Our results confirmed the report of previous investigators indicating a relationship between obesity and hypertensive risk (Ko et al 1997; Ledoux et al 1997; Cox et al 1998; Okosun et al 1999). Our finding on the risk ratio of hypertension based at different levels of BMI was without gender bias. The adoption of varying cut-off points or lack of standardization or categorization in the definition of obesity from studies from different populations using the BMI, poses a difficulty in comparison of our result with previous investigations on relative risk for hypertension. Huang and colleagues (2002) found BMI to be closely related to cardiovascular risk factors, where overweight was defined as $23 \mathrm{~kg} / \mathrm{m}^{2}$ and obesity was defined as BMI $25 \mathrm{~kg} / \mathrm{m}^{2}$ according to the proposed BMI definition criteria for the Asia-Pacific region. Gelber and colleagues (2007) using the quintiles BMI category reported that BMI, even within the "normal" range, was consistently associated with increased risk of hypertension, they found the relative risks $(95 \% \mathrm{CI})$ of developing hypertension for men with a BMI of $22.4-23.6 \mathrm{~kg} / \mathrm{m}^{2}, 23.7-24.7 \mathrm{~kg} / \mathrm{m}^{2}$, $24.8-26.4 \mathrm{~kg} / \mathrm{m}^{2}$, and $>26.4 \mathrm{~kg} / \mathrm{m}^{2}$ to be $1.20(1.09-1.32)$, 1.31 (1.19-1.44), 1.56 (1.42-1.72), and 1.85 (1.69-2.03), respectively. Nevertheless, the result of this study agrees with the findings of previous investigators that have shown that the risk of hypertension increased with increasing BMI (Dyer and Elliott 1989; Pi-Sunyer 1991; Jousilahti et al 1995; Kannel et al 1996; Seidell et al 1996; William et al 1996;
Kopelman 2000; Hu and Tian 2001; Huang et al 2002; Gelber et al 2007). However, the increased risks associated with obesity have been shown to occur at lower BMIs in Asians because these populations are predisposed to visceral or abdominal obesity (Wang et al 1992, 1994; Deurenberg et al 1999).

From the result of this study, the risk of hypertension was about six times among those with obesity compared with underweight, while it was approximately two times for obese persons than those in the normal weight and overweight categories respectively.

Among the males, the risk of hypertension was approximately three times among those with obesity compared with the underweight and the normal weight persons, respectively. The risk was about two times higher for obese persons than those in the overweight categories. Among the females, the risk of hypertension was approximately six times among those with obesity compared with the underweight while was about three times higher among obese women than their normal weight counterparts. The risk was about two times higher for obese persons than those in the overweight categories.

In a Finnish study, $\mathrm{Hu}$ and colleagues (2004) found risk ratios of hypertension based at different levels of BMI $(<25,25-29.9$, and $\geq 30)$ to be $1.00,1.18$, and 1.66 for men; and 1.00, 1.24, and 1.32 for women, respectively. In another study among rural Chinese, $\mathrm{Hu}$ and colleagues (2000) found the adjusted odds ratio for hypertension across quintiles of BMI (quintile medians: 18.0, 19.4, 20.6, 21.8, and 24.0 ) to be $1.0,1.34,2.46,2.61$, and 4.90 , respectively (95\% CI: 3.20-7.50). From our study, Nigerians demonstrated a higher risk for hypertension according to different levels of BMI for both males and females than those reported in both the Finnish (Hu et al 2004) and Chinese studies (Hu et al 2000). This study showed that increasing BMI led to significantly higher risks of hypertension in almost all age groups. In the age groups older than 80 years, however, the relationships were statistically inconsistent.

\section{Conclusion}

Body mass index seems to have a strong association with the risk of hypertension among Nigerians aged 20-80 years without gender discrimination. In Nigeria, we found a strong gradient between higher BMI and increased risk of hypertension. However, the associations are statistically inconsistent for the elderly. Therefore, approaches to reduce the risk of hypertension may include prevention of overweight and obesity. 


\section{Disclosure}

The authors report no conflicts of interest in this work.

\section{References}

Assmann G. 1993. Lipid metabolism disorders and coronary heart disease: primary prevention, diagnosis, and therapy guidelines for general practice. 2nd ed. Munich: MMV Medizin Verlag, p. 281.

Belahsen R, Mziwira M, Fertat F. 2004. Anthropometry of women of childbearing age in Morocco: body composition and prevalence of overweight and obesity. Public Health Nutr, 7:523-30.

Bonorra E, Zenere M, Branzi P, et al. 1992. Influence of body fat and its regional localization on risk factors for atherosclerosis in young men. Am J Epidemiol, 135:1271-8.

Bose K, Ghosh A, Roy S, et al. 2003. Blood pressure and waist circumference: an empirical study of the effects of waist circumference on blood pressure among Bengalee male jute workers of Belur, West Bengal, India. J Physiol Anthropol Appl Human Sci, 22:169-73.

Chobanian AV, Bakris GL, Black HR, et al. 2003. National Heart, Lung, and Blood Institute Joint National Committee on Prevention, Detection, Evaluation, and Treatment of High Blood Pressure; National High Blood Pressure Education Program Coordinating Committee. The Seventh Report of the Joint National Committee on Prevention, Detection, Evaluation, and Treatment of High Blood Pressure: the JNC 7 report. JAMA, 289:2560-72.

Cox BD, Whichelow MJ, Prevost AT. 1998. The development of cardiovascular disease in relation to anthropometric indices and hypertension in British adults. Int J Obes Relat Metab Disord, 22:966-73.

Deurenberg-Yap M, Yian TB, Kai CS, et al. 1999. Manifestation of cardiovascular risk factors at low levels of body mass index and waistto-hip ratio in Singaporean Chinese subjects. Asia Pacific. J Clin Nutr, 8:177-83.

Dyer AR, Elliott P. 1989. The INTERSALT study: Relations of body mass index to blood pressure. INTERSALT Co-operative Research Group. J Hum Hypertens, 3:299-308.

Gelber RP, Gaziano JM, Manson JE, et al. 2007. A prospective study of body mass index and the risk of developing hypertension in men. $A m$ J Hypertens, 20:370-7.

Guagnano MT, Ballone E, Colagrande V, et al. 2001. Large waist circumference and risk of hypertension. Int J Hypertens, 25:1360-4.

Guagnano MT, Merlitti D, Murri R, et al. 1994. Ambulatory blood pressure monitoring in evaluating the relationship between obesity and blood pressure. J Hum Hypertens, 8:245-50.

Gupta R, Mehrishi S. 1997. Waist-hip ratio and blood pressure correlation in an urban Indian population. $J$ Indian Med Assoc, 95:412-15.

Gus M, Fuchs SC, Moreira LB, et al. 2004. Association between different measurements of obesity and the incidence of hypertension. $\mathrm{Am}$ J Hypertens, 17:50-3.

Hall JE. 1994. Renal and cardiovascular mechanisms of hypertension in obesity. Hypertension, 23:381-94.

Han TS, Seidell JC, Curral JEP, et al. 1997. The influence of height and age on waist circumference as an index of adiposity in adults. Int $J$ Obes Relat Metab Disord, 21:83-9.

Han TS, van Leer EM, Seidell JC, et al. 1995. Waist circumference action levels in the identification of cardiovascular risk factors: prevalence study in a random sample. $B r$ Med $J, 311: 1401-5$.

Hsieh SD, Yoshinaga H, Muto T, et al. 2000. Health risks among Japanese men with moderate body mass index. Int J Obes Relat Metab Disord, 24:358-62.

Hu FB, Wang B, Chen C, et al. 2000. Body mass index and cardiovascular risk factors in a rural Chinese population. Am J Epidemiol, 151:88-97.

Hu G, Tian H. 2001. A comparison of dietary and non-dietary factors of hypertension and normal blood pressure in a Chinese population. J Hum Hypertens, 15:487-93.
Hu G, Barengo NC, Tuomilehto JT, et al. 2004. Relationship of physical activity and body mass index to the risk of hypertension: A prospective study in Finland. Hypertension, 43:25.

Huang KC, Lin WY, Lee LT, et al. 2002. Four anthropometric indices and cardiovascular risk factors in Taiwan. Int J Obes Relat Metab Disord, 26:1060-8.

Jousilahti P, Tuomilehto J, Vartiainen E, et al. 1995. Body mass index, blood pressure, diabetes and the risk of anti-hypertensive drug treatment: 12-year follow-up of middle-aged people in eastern Finland. $J$ Hum Hypertens, 9:847-54.

Kadiri S, Walker O, Salako BL, et al. 1999. Blood pressure, hypertension and correlates in urbanised workers in Ibadan, Nigeria: a revisit. J Hum Hypertens, 13:23-7.

Kamadjeu RM, Edwards R, Atanga JS, et al. 2006. Anthropometry measures and prevalence of obesity in the urban adult population of Cameroon: an update from the Cameroon Burden of Diabetes Baseline Survey. BMC Public Health, 6:228.

Kannel WB, D'Agostino RB, Cobb JL. 1996. Effect of weight on cardiovascular disease. Am J Clin Nutr, 63(3 Suppl):S419-22.

Kaufman JS. Asuzu MC, Mufunda J, et al. 1997. Relationship between blood pressure and body mass index in lean populations. Hypertension, 30:1511-16.

Ko GT, Chan JC, Woo J, et al. 1997. Simple anthropometric indexes and cardiovascular risk factors in Chinese. Int J Obes Relat Metab Disord, 21:995-1001.

Kopelman PG. 2000. Obesity as a medical problem. Nature, 404:635-43.

Ledoux M, Lambert J, Reeder BA, et al. 1997. Correlation between cardiovascular disease risk factors and simple anthropometric measures. Canadian Heart Health Surveys Research Group. CMAJ, 157(Suppl 1): S46-53.

Mabadeje AF. 1999. WHO-ISH Guidelines for the management of hypertension complications in Africa: The Nigerian experience. Clin Exp Hypertens, 21(5-6):671-81.

Okosun IS, Forrester TE, Rotimi CN, et al. 1999. Abdominal adiposity in six population of West African descent: prevalence and population attributable fraction of hypertension. Obes Res, 7:453-62.

Olatunbosun ST, Kaufman JS, Cooper RS, et al. 2000. Hypertension in a black population: prevalence and biosocial determinants of high blood pressure in a group of urban Nigerians. J Hum Hypertens, 14:249-57.

Pearson TA. 1999. Cardiovascular diseases in developing countries: myth, realities and opportunities. 3:95-104.

Pi-Sunyer FX. 1991. Health implications of obesity. Am J Clin Nutr, $53: 1595 \mathrm{~s}-1603 \mathrm{~s}$

Pi-Sunyer FX. 1993. Medical hazards of obesity. Ann Intern Med, 119:655-60

Seidell JC, Cigolini M, Deslypere JP, et al. 1991. Body fat distribution in relation to serum lipids and blood pressure in 38-year-old European men: the European fat distribution study. Atherosclerosis, 86:251-60.

Seidell JC, Verschu Ren WM, et al. 1996. Overweight, underweight, and mortality. A prospective study of 48,187 men and women. Arch Intern Med, 156:958-63.

Sergeant LA, Bennett FI, Forrester TE, et al. 2002. Predicting incident diabetes in Jamaica: the role of anthropometry. Obes Res, 10:792-8.

Shahbazpour N. 2003. Prevalence of overweight and obesity and their relation to hypertension in adult male university students in Kerman, Iran. Int J Endocrinol Metab, 2:55-60.

Shanthirani CS, Pradeepa R, Deepa R, et al. 2003. Prevalence and risk factors of hypertension in selected South Indian population - the Chennai Urban Population Study. J Assoc Physicians India, 51:20-7.

Stamler J. 1991. Epidemiologic findings on body mass and blood pressure in adults. Ann Epidemiol, 1:347-62.

Wang J, Russell-Aulet M, Mazariegos M, et al. 1992. Body fat by dual photon absorptiometry (DPA): comparisons with traditional methods in Asians, Blacks and Caucasians. Am J Hum Biol, 4:501-10 
Wang J, Thornton JC, Russell M, et al. 1994. Asians have lower body mass index but higher percent body fat than do Caucasians: comparisons of anthropometric measurements. Am J Clin Nutr, 60:23-8.

William BK, Ralph BD, Janet LC. Effect of weight on cardiovascular disease. Am J Clin Nutr, 63:419s-422s.

[WHO] World Health Organization; Sethi D, Habibula S, McGee K, et al. (eds). 2004. Guidelines for conducting community surveys on injuries and violence. Geneva: World Health Organization.

[WHO] World Health Organization. 1997. Obesity: preventing and managing the global epidemic. Report of a WHO Consultation. Presented at: the World Health Organization; June 3-5, 1997; Geneva, Switzerland. Publication WHO/NUT/NCD/98. 1:1998.
[WHO-ISH] World Health Organization-International Society of Hypertension Guidelines for the Management of Hypertension. 1999. 1999 World Health Organization-International Society of Hypertension Guidelines for the Management of Hypertension. Guidelines Subcommittee. Hypertens, 17:151-83.

Yekeen LA, Sanusi RA, Ketiku AO. 2003. Prevalence of obesity and high level of cholesterol in hypertension: Analysis of data from the University College Hospital, Ibadan. African J Biomed Res, 6:129-32. 